\title{
UIT DE EERSTE DAGEN VAN DEN WEST-INDISCHEN SLAVENHANDEL
}

DOOR

\author{
C. K. KESLER
}

Het is overbekend, dat de pogingen van Fray Bartolomé de las Casas om de Indianen te beschermen tegen geheele uitroeiing ten gevolge van de meedoogenlooze behandeling door de Spanjaarden in de eerste jaren na de ontdekking van Amerika, de, door hem niet bedoelde, aanleiding zijn geweest tot het op groote schaal invoeren van Afrikaansche negerslaven in de Spaansche en later ook in andere koloniën in de Nieuwe Wereld.

Aanvankelijk was dit in de eerste geheel verboden, of althans aan zeer beperkende bepalingen onderhevig, daar voor het invoeren van verschillende artikelen een speciale vergunning van de Kroon noodig was. Onder deze artikelen worden in een koninklijke ordonnantie voor het Casa de Contratación te Sevilla, dat belast was met alle zaken, die export van waren uit het moederland en import in de koloniën betroffen, als verboden waren voor de koloniën opgesomd: plata, monedas, caballos, yeguas, esclavos, armas, guanines" 1 ).

De gronden voor het verbod van eenige dezer artikelen zijn niet zeer duidelijk; wat de slaven betreft, waren deze in de eerste plaats te vinden in religieuse overwegingen. Ofschoon slavernij in Spanje zelf wel bestond - er waren o.a. negers uit Guinea, die van de Portugeezen gekocht werden, en Moorsche slaven uit Noord-Afrika - waren toch de Kerk en de geestelijkheid tegen de slavernij gekant. En Ferdinand en Isabella, trouwe aanhangers van de Kerk, deden dus het hunne, om invoering ervan in de, nieuw verworven, gebieden in Amerika te verhinderen, vooral ook, daar zij de taak, die zij daar voor zich zagen, nl. de heidensche inboorlingen tot het Christendom en de beschaving te brengen, zou kunnen bemoeilijken.

1) Zilver, munten, hengsten, merries, slaven, wapenen, galanteriewaren. 
Later werd men in dit opzicht minder scrupuleus en werd de uitvoer van zwarte slaven een privilege van favorieten van de Kroon, of van particuliere maatschappijen, welke laatste gewoonlijk een belangrijk bedrag voor iederen geëxporteerden neger hadden te betalen. Daardoor werd in het midden van de 17e eeuw, toen per hoofd 30 ducaten benevens een belasting van 20 realen betaald moest worden, het voordeel, dat de negerhandel opleverde, een belangrijke bron van inkomsten voor de Kroon, die zij ongaarne opgaf. Deze rechten moesten vooraf te Sevilla voldaan worden; kon dit om de eene of andere reden niet geschieden, dan was de handelaar na verkoop van zijn slaven in de koloniën 40 ducaten en 30 realen belasting verschuldigd 1). Uitvoer van één soort slaven bleef echter tot laat in de $17 \mathrm{e}$ eeuw streng verboden, nl. die der zg. „esclavos de levante”, d.w.z., die welke op Sardinië of de Balearen gekocht waren, Moorsche of Joodsche halfbloeden, of bekeerden tot den Mohammedaanschen godsdienst.

De richtige naleving van deze decreten was echter in de Amerikaansche gewesten niet te verkrijgen; al werd ook minutieus de geheele handel in het moederland geregeld, overtreding van de voorschriften was in de koloniën regel, gehoorzamen eraan uitzondering. Een voorbeeld van de zorgvuldige regeling van den export van slaven biedt een decreet van 1563, waarin den schippers verboden werd, slaven als bedienden aan boord te hebben. Dit kon blijkbaar toch niet belet worden, waarom in 1572 een decreet verscheen, waarbij twee negers uit Guinea veroorloofd werden, mits per hoofd 50.000 maravedis betaald werden, als garantie, dat zij weer naar Spanje terug gevoerd zouden worden.

Export uit Spanje werd dus zooveel mogelijk tegen gegaan; import in de koloniën was echter weldra niet meer te beletten. Eerst was, zooals bekend is, getracht, zoowel op Hispaniola als elders, de Indianen tot arbeid voor de nieuwe bezitters te dwingen. Op het eerstgenoemde eiland stierf echter de oorspronkelijke bevolking met onrustbarende snelheid uit. Toen werd getracht, elders Indiaansche slaven op te vangen en wendden de slavenhalers zich naar de kust van Florida en weldra ook naar die van andere streken langs de Golf van Mexico en van de Caraïbische Zee. Hier kwamen zij echter herhaaldelijk in conflict met vreedzamer kolo-

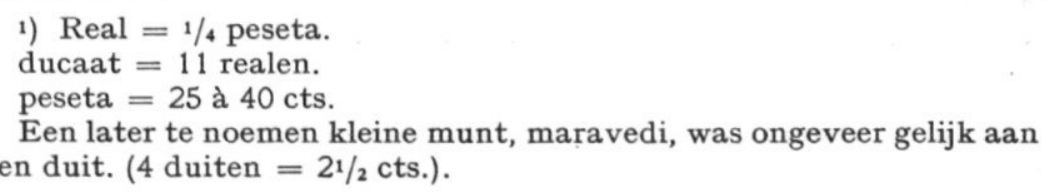


nisten, die dan klachten tot de regeering in het moederland richtten, welke klachten, in verband met de afkeerige gezindheid der Spaansche autoriteiten ten opzichte der slavernij gereedelijk gehoor vonden.

De Indianen waren oorspronkelijk volgens decreten van 1511 en 1513 onderscheiden in beschermde (guatiaos) en wilde (caribes). Om nu, in verband met de ontvangen klachten, te doen nagaan, of de, op de Indianen betrekking hebbende, verordeningen van kracht dienden te blijven, of wellicht wijziging behoefden, zond de regeering in 1519 een rechterlijk ambtenaar, Rodrigo de Figueras naar Hispaniola met opdracht, deze zaak definitief te regelen. De door hem gemaakte regeling, die door de regeering werd goedgekeurd, maakte, dat de inboorlingen van Hispaniola (Santo-Domingo) in het vervolg vrij afdoende beschermd werden. De kuststreken van Zuid-Amerika en de daarvóór liggende eilanden werden echter aan de slavenhalers overgelaten ${ }^{1)}$. Hier werden nu gedurende een reeks van jaren de Indianen opgevangen en naar het eiland Cubagua gevoerd, waar zij aan gegadigden verkocht werden. Onder deze vrij gelaten eilanden behoorden ook de drie eilanden Bonaire, Curaçao en Aruba. Van deze en andere eilanden konden de slavenhalers dus de Indianen opvangen en wegvoeren, soms bij wijze van straf voor veronderstelde onbeschaafde handelingen. Zoo werd in 1513 aan Pedrasias Davila 2) vergund, de inwoners der eilanden Isla Fuerte, Baren, San Bernardo en Santa Cruz tot slaven te maken „por razon que comen carna humana” (omdat zij menschenvleesch eten). Dit laatste nu schijnen de

1) Door De Figueras werden als voor aanvallen en rooftochten verboden eilanden opgesomd: Trinidad, de Lucayes, Barbados, Gigantes en Margarita. De „Islas de los Gigantes” zijn de eilanden Bonaire, Curaçao en Aruba.

2) Pedrasias Davila was in 1514 naar Amerika gekomen met eenige schepen, waaraan bijzondere zorg besteed was; zij waren nl. met looden platen bedekt, ten einde ze te beschermen tegen de tropische paalwormen, die aan de schepen van Columbus zooveel schade hadden toegebracht. $Z$ ijn doel was, een nederzetting te stichten aan de landengte aan de kust van den Pacific. Van de Regeering kreeg hij daarna opdracht, een weg aan te leggen van Santa-Maria del Darién (aan de O.kust) naar de Golf van San Miguel (aan de W.-kust) in het belang van den specerijhandel met Oost-Indië, waarvan men in het eerste vierde deel van de $16 \mathrm{e}$ eeuw groote verwachtingen had.

In 1517 werd op zijn bevel Vasco Nuñez de Balboa, de ontdekker van den Stillen Oceaan, als oproerling onthoofd.

In 1519 stichtte hij de stad Panama en werd in 1526 benoemd tot Gouverneur van Castilla del Oro.

West-Indische Gids XXII 
meesten der inboorlingen van onze tegenwoordige Benedenwindsche eilanden niet gedaan te hebben. Toch werden zij opgevangen en weggevoerd. Zoo kwam het, dat onder de 200 Indianen, die bij koninklijk besluit van 15 Juli 1511, bij zijn aankomst op Santo Domingo, aan Juan de Ampiés, benoemd tot koninklijken „factor”, als „repartimiento” werden toegewezen, er ook eenige waren, die van de laatstgenoemde eilanden afkomstig waren.

Juan de Ampiés 1) behoorde door deze benoeming tot de drie „oficiales reales" (de beide andere waren de „tesorero " ende „contador"), was daardoor een der voornaamste ambtenaren op Santo Domingo en dus een man van invloed. De werkzaamheden van den koninklijken factor in de Amerikaansche koloniën bestonden destijds hoofdzakelijk in het toezicht houden op alle ladingen, die uit het moederland in Amerika geïmporteerd en op die, welke vandaar naar Europa verzonden werden. Wat de eerste betreft, moest de factor de door den schipper afgeteekende manifesten tegen reçu in ontvangst nemen en de lading controleeren. De reçus moesten bij terugkeer in Sevilla bij het Casa worden ingeleverd. Thuisvarende schepen werden eveneens gecontroleerd en de schipper ontving van den factor een schriftelijke instructie met betrekking tot de aflevering van zijn lading.

Juan de Ampiés schijnt over het algemeen den Indiaanschen slaven welgezind geweest te zijn. Uit hun mededeelingen werd het hem duidelijk, dat het zeer onjuist was, de vreedzame Arowakken, waartoe de meesten der van de Benedenwindsche eilanden weggevoerde Indianen behoorden, geheel gelijk te stellen met hun doodsvijanden, de krijgshaftige en , naar het schijnt, menschenetende Caraïben. Het plan kwam toen bij hem op, nadat hij erin geslaagd was, een zeker aantal van de eersten, mannen, vrouwen en kinderen, te verkrijgen, deze weder naar hun, vrijwel ontvolkte, eilanden terug te voeren en daar onder Spaansch toezicht een kolonie te stichten.

Hiervoor was ten slotte de toestemming van de Kroon noodig, waaraan belangrijke kosten verbonden waren. Om deze te ontgaan wist Juan de Ampiés echter een voorloopige goedkeuring van zijn plan en de noodige middelen tot uitvoering ervan van de audiencia (het plaatselijke gerechtshof) te Santo-Domingo te verkrijgen. Dit kostte hem niet veel moeite, daar de werkzaamheden van de oficiales reales en die van den president en de leden der audiencia vaak elkander aanvulden of in elkander grepen. Belang-

1) Zijn naam wordt op verschillende wijzen gespeld: Ampiés schijnt de juiste te zijn. 
rijk voor het slagen der kolonisatie was het, dat het voor het vervolg aan slavenhalers verboden werd, zich op de drie eilanden te vertoonen, waardoor zich daar betere toestanden konden ontwikkelen.

De eilanden schijnen in dien tijd veel rijker aan houtgewas geweest te zijn, dan tegenwoordig. Een der voornaamste voortbrengselen, waarom zij, ook nadat de meeste Indianen er reeds waren weggevoerd, nog door schepen aangedaan werden, was het Brazielhout 1), dat er overvloedig voorkwam, evenals in het land achter Coro aan de overzijde. Het kolonisatie-plan van Juan de Ampiés was allerminst uitsluitend op philanthropische grondslagen gebaseerd; een zijner doeleinden was, van dezen houtrijkdom voordeel te trekken, o.a. door het werk van zijn Indianen. Te zamen toch met een zekeren JunaFernandez de Castro had hij op 29 November 1527 van de Spaansche regeering een monopolie voor het kappen en uitvoeren van dit hout uit het geheele Spaansche koloniale gebied - dat zich destijds hoofdzakelijk nog tot de Antillen en eenige kuststreken beperkte - weten te verkrijgen.

Door zijn Arowaksche kolonisten kwam Ampiés ook in aanraking met hun stamgenooten op het vaste land en hij vatte het voornemen op, zijn bemoeiingen ook tot daar uit te breiden. Ook hiervoor verkreeg hij de voorloopige bewilliging der audiencia en hierop steunende, werd op het feest van de H. Anna (2 6Juli) 1527 in het daar bestaande Indianendorp de eerste steen voor de stad Coro gelegd. De eilanden Aruba, Curaçao en Bonaire had hij, zooals boven gezegd werd, reeds enkele jaren in bezit gehad en bij decreet van 15 November 1526 was de koninklijke goedkeuring aan de voorloopige toewijzing door de audiencia gehecht. Ampiés' doel was blijkbaar, op dezelfde wijze, als dat met de Benedenwindsche eilanden geschied was, met de minste kosten ook vasten voet in Venezuela te verkrijgen en te trachten, zijn vestiging daar eveneens achteraf door de Kroon te doen goedkeuren. Het is intusschen hoogst twijfelachtig, of hij daarbij uitsluitend door menschlievende overwegingen ten opzichte der Indiaansche be-

1) Brazielhout, ook wel genoemd Campèche- of stokvischhout (Haematoxylon Brasiletto Karst), werd in de 17e eeuw in belangrijke hoeveelheden o.a. uit Brazilië naar de Republiek uitgevoerd. Fijngemalen of geraspt werd er een roode verstof uit bereid. Dit malen geschiedde o.a. door de bemanningen der thuisvarende schepen op de reis, of in Amsterdam door gevangenen. Vandaar de naam ,"het roode dorp” of "het rasphuis", die het vroegere tuchthuis op den Heiligen Weg in de volksmond droeg; de vrouwen-gevangenis heette wegens den daar verrichten arbeid het spinhuis. 
volking geleid werd; veeleer is het waarschijnlijk, dat hij naast zijn kolonisatie en houthandel ook wel degelijk den winstgevenden handel in Indiaansche slaven op het oog had.

De gelegenheid dartoe was in Venezuela zeer gunstig. De kuststreken waren er voor de slavenhalers vrij gelaten en de Indianenstammen in het binnenland leefden met elkander in voortdurenden strijd, waardoor het betrekkelijk gemakkelijk was, krijgsgevangenen van eventueele overwinnaars als slaven te koopen 1). De goede verstandhouding, waarin Ampiés tot een der machtigste hoofden aan de kust, den Cacique van Coro 2), stond, maakte het voor hem waarschijnlijk, dat hij door een dergelijken handel belangrijke voordeelen zou kunnen behalen. Er wordt bovendien vermeld, dat hij verschillende bekende en geoefende slavenjagers in zijn dienst had.

Met Venezuela had hij echter niet het succes, dat hem met de eilanden ten deel gevallen was. De audiencia te Santo Domingo legde hem wederom geen moeilijkheden in den weg, maar liet de uitvoering van zijn plannen oogluikend en waarschijnlijk met geheime instemming toe. Er waren echter ernstige concurrenten in Santo-Domingo, die eveneens het oog op Venezuela hadden laten vallen en die geheel van Ampiés' plannen op de hoogte waren. Zij waren des te gevaarlijker, daar zij in rechtstreeksche verbinding met de regeering in Spanje stonden. Deze concurrenten waren leden der firma Ehinger en Hiëronymus Sailer, die allen in nauwe verbinding stonden met het machtige bankiershuis Welser te Augsburg, waaraan Karel V groote financieele verplichtingen had. Dit huis had grooten invloed aan het keizerlijke hof, o.a. door den steun, dien het den Keizer verschaft had, bij de voorbereiding van diens verkiezing in 1519. Wel was deze niet zóó belangrijk geweest als het aandeel, dat het huis Fugger erin gehad had, maar Karel V had toch alle aanleiding, om ook het huis Welser te ontzien en het bij voorkomende gelegenheden op zijn beurt te begunstigen. Het had dan ook reeds verschillende voorrechten o.a. met betrekking tot den overzeeschen handel, als vergunning tot het stichten en onderhouden van een factorij te Sevilla, beschikking over een pakhuis aan de haven en vergunning tot het vestigen van een factorij

1) Zulke gekochte krijgsgevangenen werden dan gerekend te behooren tot die Indianen, die ontoegankelijk waren voor de beschaving en onwillig om tot het Christendom bekeerd te worden.

2) Deze Cacique van Coro wordt door Ampiés genoemd Naura of Anaura; in een ander geschrift (van 1548) waarin zijn dood vermeld wordt, heet hij Manaore. 
op Santo-Domingo. Deze schijnt eerst door Heinrich en later door Ambrosius Ehinger beheerd te zijn. In 1528 was de laatste daar in functie.

Heinrich Ehinger 1) en Hiëronymus Sailer verkregen in dat jaar een concessie van Karel $\mathrm{V}$ voor de stichting van een kolonie in Venezuela en bewerkten bij den Keizer de uitvaardiging op 8 October 1529 van een algemeen verbod aan anderen dan de concessionarissen, om zich met de zaken der nieuwe kolonie te bemoeien. Dezen lieten nu hunnerzijds in Sevilla en in alle belangrijke Amerikaansche havens omroepen, dat het uitdrukkelijk aan alle buitenstaanders verboden was, schepen naar Venezuela te zenden en deze daar te doen ankeren. Drie jaar later moest echter deze uitsluiting van alle, ook Spaansche, kooplieden op koninklijk bevel herroepen worden (7 Februari 1531). De Venezolaansche kolonie werd, naar het schijnt, daar de exploitatie ervan de financieele krachten van Ehinger en Sailer te boven ging, weldra door het huis Welser overgenomen. Hierdoor kwam Juan de Ampiés in conflict met het machtige bankiershuis, welk conflict een persoonlijk karakter kreeg, doordat Ambrosius Ehinger, destijds vertegenwoordiger der Welsers op Santo-Domingo, als leider der nieuwe kolonie werd aangewezen.

Ampiés protesteerde bij de Regeering tegen de toewijzing van Venezuela aan de Duitschers en voerde als gronden daarvoor aan, dat hij zich er in overeenstemming met de inboorlingen en hun hoofden reeds gevestigd had, dat deze kolonisatie-poging hem groote kosten veroorzaakt had, en, dat hem herhaaldelijk te kennen gegeven was, dat hij de officieele erkenning van zijn kolonie mocht verwachten. Zijn protest had echter niet het door hem gewenschte gevolg 2). De Regeering vroeg het advies van de audien-

1) De Ehingers waren uit Konstanz afkomstig. Drie gebroeders, stonden omstreeks 1528 in nauwe betrekking tot het huis Welser, nl. Heinrich, Georg en Ambrosius. De eerste werd in 1530 schatmeester van Karel V en was in 1535 Ridder in de Orde van Santiago (een der drie geestelijke ridderorden in Spanje; de beide andere waren die van Alcantara en van Calatrava).

Georg was in 1530 in Venezuela en verbrak kort daarna, evenals zijn broeder Heinrich de relaties met het huis Welser.

Ambrosius hield deze aan en was 1528-1534 Stadhouder en Opperbevelhebber in Venezuela, toen dit in bezit der Welsers gekomen was, onder den naam Dalfinger. (De namen van vele Duitschers werden door de Spanjaarden vaak op allerlei wijzen verbasterd.)

${ }^{2}$ ) In dit protest vermeldt Ampiés, dat Diego Colón, Onderkoning en Gouverneur van Hispaniola, de eilanden Aruba, Curaçao en Bonaire voor „islas inútiles" verklaard had. 
cia te Santo-Domingo en wenschte in het bijzonder ingelicht te worden, of inderdaad aan Ampiés officieele toezeggingen gedaan waren. Het antwoord daarop kon niet anders dan ontkennend luiden. Ampiés bleef toen alleen in het bezit der eilanden Aruba, Curaçao en Bonaire en de toewijzing van Venezuela aan de Welsers bleef gehandhaafd. Hij heeft toen nog, niet zonder voorkennis der audiencia, die op zijn hand en tegen de Duitschers was, getracht, zich met geweld in het bezit van Coro te handhaven, maar moest, daar hij niet voldoende gesteund werd, het land ten slotte aan de Duitschers overlaten.

Het was intusschen steeds duidelijker geworden, dat met hoofdzakelijk Indianen, hetzij als beschermde vrijen, hetzij als slaven, het, zich steeds uitbreidende overzeesche, koloniale rijk van Spanje niet doeltreffend en, op voor het moederland voordeelige, wijze geëxploiteerd kon worden. Steeds dringender werden de aanvragen der kolonisten om arbeiders voor landbouw- en veeteelt-bedrijven, maar vooral voor de ontginning der zilvermijnen en der goudvelden. Voor de laatste werkzaamheden is er zelfs een proef genomen met invoering van Duitsche bergwerkers, volgens een contract, dat met de Welsers gesloten werd. Er werd echter voornamelijk aangedrongen op invoering van negerslaven. Ferdinand en Isabella hadden, voornamelijk uit godsdienstige overtuiging, welke vooral bij de Koningin den doorslag gaf, deze zooveel mogelijk tegen gehouden; onder de regeering van Karel V kwam hierin verandering. Reeds Ferdinand de Katholieke had zich gedrongen gezien, in 1510 aan den factor van het Casa de Contratación op te dragen, overeenkomstig den wensch der kolonisten, 50 negerslaven naar Santo-Domingo te zenden, die daar publiek verkocht zouden worden, om als arbeiders in de goudwasscherijen dienst te doen. Daarna werden er nog 200 gezonden en zeer waarschijnlijk hebben in volgende jaren nog meer transporten met goedvinden en op last der regeering plaats gehad. In die periode werd het verbod van invoering van negerslaven, dat intusschen volstrekt niet officieel ingetrokken was, met zoo weinig nadruk gehandhaafd en overtredingen ervan òf zeer licht bestraft, òf zelfs geheel onopgemerkt gelaten, dat het eigenlijk practisch niet meer bestond.

Deze onwettige handel verkreeg zulk een omvang, dat de Kardinaal-Regent Jimenez het noodig oordeelde, met nadruk aan de wettelijke voorschriften te herinneren. Tevens zond hij in 1516 een commissie van drie Paters Hieronomyten naar Amerika met opdracht o.a., zich te overtuigen, of de inboorlingen voldoende beschermd werden. Aan deze commissie werd Las Casas als „Pro- 
tector de los Indios" toegevoegd, om haar van advies te dienen en aan de Regeering rapport uit te brengen. Het optreden der paters bevredigde Las Casas geenszins en, daar hij door eigen ervaringen ervan overtuigd was, dat het onontbeerlijk was, de noodige werkkrachten voor de koloniën te verkrijgen, deed hij toen het voorstel, grootere vrijheid tot invoer van negerslaven te verleenen. Dit kwam geheel met de wenschen der kolonisten overeen, wat tot uiting kwam in een stroom van petities aan den Raad van Indië in Spanje, waarin verzocht werd den invoer van slaven geheel vrij te laten.

Voorloopig werden toen, ter voldoening aan de verlangens der aanvragers verschillende vergunningen tot uitvoer van negers uit Spanje verleend, vaak van aanzienlijke aantallen, soms zelfs van eenige honderden. En op grond van, uit de koloniën ontvangen rapporten, besliste de regeering, dat een aantal van 4000 slaven voorloopig voldoende zou zijn. Het Spaansche gebied omvatte in 1517 , toen dit besluit genomen werd, nog slechts de Groote Antillen en enkele streken op het vasteland en aan de landengte. Deze toegestane 4000 slaven zouden aldus verdeeld worden: 1400 voor Española, 700 voor Cuba, 500 voor Jamaica, 300 voor Portorico, 500 voor Castilla del Oro (op de landengte) en 600 voor Mexico.

Terwijl de uitvoering van deze regeling voorbereid werd, kwam de jonge Koning Karel in Spanje aan en deze verleende aan een zijner gunstelingen, den Gouverneur van Bresse, Laurence de Gorrebot, het voorrecht, den aanvoer van de 4000 slaven te verzorgen. Deze verkreeg vrijstelling van het betalen van alle rechten (hoofdgeld en uit- en invoerrecht) en tevens de vergunning, de negers aan de kust van Guinea te koopen en in te schepen, waarna ze zonder contrôle te Sevilla of op de Canarische eilanden rechtstreeks naar Amerika vervoerd mochten worden. De begunstigde had alle reden, zijn Koning voor dit gunstbewijs erkentelijk te zijn, want de waarde ervan werd kort na de verleening ervan geschat op 25.000 ducaten. Er is wel beweerd, dat de Gouverneur van Bresse het monopolie voor dat bedrag onmiddellijk aan een consortium van Genueesche kooplieden verkocht heeft; dit schijnt echter niet geheel juist te zijn. Waarschijnlijker is het, dat hij zich door het verleenen van licenties tegen betaling aan derden belangrijke inkomsten heeft weten te scheppen en zeker is het, dat de monopolist uit den handel in licenties, die zich spoedig ontwikkelde en, waaraan zoowel Spanjaarden als Genueezen deelnamen, belangrijke inkomsten trok. Hij verzocht dan ook in 1522 of '23, nogmaals zulk een monopolie voor de levering van nog 4000 sla- 
ven te mogen verkrijgen. Gedurende eenige jaren werd zoo de handel in licenties hoofdzaak en raakte de eigenlijke levering der slaven eenigszins op den achtergrond. Het arbeiders-vraagstuk in de koloniën was daardoor nog allerminst opgelost, vooral, daar de Regeering zich strikt hield aan de bepalingen van het monopolie en iederen particulier, die een aanvraag indiende om, al was het ook maar enkele, slaven te mogen invoeren, naar de agenten van den concessionaris verwees. Deze lieten zich goed betalen en zoo kwam het voor, dat er soms 4 à 5 maal zooveel als vroeger voor den invoer van een neger betaald moest worden.

De kolonisten klaagden dan ook steen en been, dat de slaven voortdurend duurder werden en haast niet te verkrijgen waren. Dit had ten gevolge, dat op aandringen van de audiencia te SantoDomingo het monopolie van den Gouverneur van Bresse op 17 November 1523 werd opgeheven. Het eerste contingent van 4000 negers schijnt inmiddels geleverd, maar bleek spoedig niet voldoende te zijn. Er trad nu een ander systeem in werking. De Regeering trok de contrôle over de levering der benoodigde slaven weer aan zich, maar, daar zij in voortdurende geldverlegenheid zat, ging zij ertoe over, evenals dat met andere zaken, bv. bergwerken in Spanje, geschiedde, een contract of ,asiento" met particulieren af te sluiten. De asientisten hadden dan een bepaald bedrag, contant of in termijnen, aan de Regeering te betalen, wat zij in den regel door middel van de voordeelen, die het asiento hun verschafte, wel ruimschoots wisten terugbetaald te krijgen.

Zulk een asiento kwam op 12 Februari 1528 te Burgos tot stand met de hierboven genoemde Heinrich Ehinger en Hiëronymus Sailer. Dezen verbonden zich binnen 4 jaren opnieuw 4000 slaven te leveren, $2 / 3$ mannen en $1 / 3$ vrouwen 1 ). Als voorschot aan de Regeering hadden de asientisten 20.000 ducaten te betalen, dus 5 ducaten per te leveren slaaf. De pachtsom kon in termijnen voldaan worden, nl. 3000 ducaten contant, 2000 in October en het saldo in termijnen van 2500 ducaten in Mei of October der volgende jaren, onverschillig, of de geheele hoeveelheid slaven reeds geleverd was. Als maximumprijs per slaaf in de koloniën werd 50 ducaten vastgesteld.

Dit slaven-asiento hield verband met de boven vermelde kolo-

1) Daar in Amerika vooral vraag was naar mannelijke werkkrachten, werd bij deze gelegenheid een vroegere bepaling, die voorschreef, dat van ieder transport steeds de helft mannen en de andere helft vrouwen moesten zijn, losgelaten. Deze laatste bepaling kwam o.a. in het tweede monopolie van den Gouverneur van Bresse voor. 
nisatiepogingen in Venezuela. Hiervoor in het bijzonder verkregen de asientisten op hun verzoek nog vergunning, behalve de 4000 , voor de Spaansche koloniën gecontracteerde, slaven er nog 800 voor hun eigen kolonie te mogen invoeren. Daar echter de Duitsche kolonisatie van Venezuela, zelfs toen het huis Welser dit belang overnam, niet slaagde, kregen de asientisten vergunning, deze 800 slaven in andere koloniale havens te verkoopen. Noodgedwongen was intusschen de Spaansche regeering gedurende een belangrijk aantal jaren afgeweken van haar systeem, alles, wat den kolonialen handel betrof, in eigen hand te houden. In de volgende eeuwen zou zij nog eenige malen daartoe genoodzaakt worden, vooral toen andere West-Europeesche natiën als concurrenten in Amerika begonnen op te treden:

Lit e r a t u r :

KonRad Haebler, Die Geschichte der Fuggerschen Handlung in Spanien. Weimar 1897.

KonRad HAEbler, Die überseeischen Unternehmungen der Welser und ihrer Gesellschaft. Leipzig, 1908.

Clarence Henry Haring, Ph. D., Trade and Navigation between Spain and the Indies. Cambridge, 1918.

Eerste Jaarlijksch verslag v. h. Geschied-, taal- en volkenkundig Genootschap, Curaçao. Amsterdam, 1897. 